\title{
ATIVIDADE ANTIMICROBIANA IN VITRO DE Arnica montana
}

\author{
In vitro antimicrobial activity of Arnica montana
}

\author{
Ana Lígia Amato1, Aloísio Cunha de Carvalho², Selene Dall' Acqua Coutinho \\ ${ }^{1}$ Médica Veterinária - Projeto de Iniciação Científica realizado no CLININFEC (G rupo de Pesquisa em Clínica e D oenças \\ Infeccio sas Veterinárias da Universidade Paulista- UNIP, cadastrado no CNPq). São Paulo, SP - Brasil. \\ 2 Prof. do Curso de G raduação em Medicina Veterinária da Universidade Paulista - UNIP. São Paulo, SP - Brasil. \\ ${ }^{3}$ Prof ${ }^{a} D$ râados Cursos de G raduação em MedicinaV Veterinária e Pós-G raduação em Imunopatologia V eterinária da Universidade \\ Paulista - UNIP. São Paulo, SP - Brasil, e-mail: selene@ uol.com.br
}

\section{Resumo}

O objetivo do presente trabalho foi pesquisar uma possível ação antimicrobiana in vitro da A rnica montana. Foram testadas cepas-padrão (ATCC) de Staphylococcus aureus, Pseudomonas aeruginosa, E nterococcus faecalis, E scherichia coli, Bacillus subtilis e $C$ andida albicans pelos métodos de diluição seriada em caldo (Concentração Inibitória Mínima) e difusão em ágar. Extrato etanólico de A . montana foi empregado nas seguintes concentrações finais: 100; 50; 25; 12,5; 6,25; 3,13; 1,56 e 0,78 mL/ mL, sendo os testes realizados em duplicata. Nos experimentos de diluição em caldo todas as cepas apresentaram crescimento nas diferentes concentrações de arnica, com exceção de B. subtilis frente a $100 \mu \mathrm{L} / \mathrm{mL}$. Na difusão em ágar não houve inibição de crescimento dos microrganismos testados, com exceção de P. aeruginosa; entretanto, essa bactéria também teve seu crescimento inibido quando se utilizou disco de papel impregnado somente com etanol. Nas condições experimentais A . montana não demonstrou ação que possa indicar sua utilização como antimicrobiano.

Palavras-chave: A rnica M ontana; Antimicrobiano; Antibiograma.

\begin{abstract}
The aim of this work was to search in vitro antimicrobial activity of Arnica montana. It has been tested standard strains (ATCC) of Staphylococcus aureus, Pseudomonas aeruginosa, Enterococcus faecalis, Escherichia coli, Bacillus subtilis and Candida albicans by broth serial dilution (Minimal Inhibitory Concentration) and agar diffusion test. Ethanolic extract of $A$. montana was used in the following final concentrations: $100 ; 50 ; 25 ; 12.5 ; 6.25 ; 3.13$; 1.56 and $0.78 \mathrm{~mL} / \mathrm{mL}$. All tests were carried out in duplicate. In serial dilution assay all
\end{abstract}


strains have presented growth at the different concentrations of A. montana, with exception of B. subtilis against $100 \mu \mathrm{L} / \mathrm{mL}$. In agar diffusion test did not have inhibition of the microorganisms, unless P. aeruginosa was tested; however, this bacterium also was inhibited when only ethanol was used. In these experimental conditions A. montana did not demonstrate good action against tested microorganisms.

Keywords: Arnica Montana; Antimicrobial activity; Antibiogram.

\section{INTRODUÇÃO}

Plantas com potencial terapêutico são empregadas pelo homem desde a antiguidade e têm se mostrado como uma alternativa à medicina tradicional $(1,2)$; portanto, é justificável a identificação dos componentes ativos eas atividades biológicas das plantas já em uso $(3,4)$.

A A rnica montana é uma planta herbácea perene, de aproximadamente $70 \mathrm{~cm}$ de altura, da família das Asteraceae e nativa das montanhas da Sibéria e da Europa Central (1). A tualmente, sua ocorrência espontâneaé muito rara, sendo cultivada em diversos países, visando sua utilização terapêutica (1).

Sua atividade regeneradora de tecidos é conhecida desde tempos remotos e, ainda hoje, sua utilização é indicada para novos fins terapêuticos (2, 3). É postulado que a arnica tenha: 1) ação analgésica com efeitos no sistema nervoso central, provavelmente decorrentes da elevação do limiar da dor; 2) anti-inflamatória, por bloqueio da liberação de histamina, o que compromete a permeabilidade vascular aumentada e 3) antiedematosa, pela aceleração do tempo de reabsorção do edema (5). No entanto, existem controvérsias que apontam para a possibilidade de seu efeito biológico se restringir apenas à atividade antiedematosa (6). Também se questiona sua ação analgésica, pois pacientes que sofreram exérese de molares, não mostraram diferenças quando se comparou o emprego de arnica e placebo (7).

0 uso tópico de arnica é indicado nas mais diversas enfermidades, particularmente naquelas com processos inflamatórios associados $(2,5,6)$; entretanto, sua utilização sistêmica carece de comprovação experimental (2). É defendido que o uso sistêmico deva ser restrito, uma vez que preparações da planta apresentam alta toxicidade e podem provocar irritação da mucosa gástrica, hepatotoxicidade, taquicardia e depressão (8).
Foi demonstrada a ação antiparasitária da arnica, que possui compostos ativos contra Plasmodium falciparum (9) e com atividade estendível ao Tripanossoma bruci e Tripanossoma cruzi (10). A despeito dessaatividade, pouco tem sido investigado em relação à sua atividade frente a patógenos de ocorrência mais comum. D entre os poucos estudos reportados, sua ação foi avaliada contra microrganismos orais e foi verificada uma inibição moderada de algumas espécies de estreptococos cariogênicos (11). Como as comunidades médica e veterinária têm assistido a um crescimento nas taxas de resistência dos microrganismos aos antimicrobianos e a uma necessidade veemente de novas moléculas terapêuticas, o objeto central desse estudo foi a pesquisa experimental da atividade antimicrobiana de A rnica montana frente cepaspadrão bacterianas e de Candida albicans.

\section{MATERIAL E MÉTODOS}

\section{Microrganismos}

A atividade antimicrobiana da A . montana foi testada em cinco espécies de bactérias: Staphylococcus aureus (ATCC-25923), Pseudomonas aeruginosa (ATCC-27853), E nterococausfaecalis (ATCC29212), E scherichia coli (ATCC-25922) e Bacillus subtilis (ATCC-6633), e um fungo, Candida albicans (NTCC-10231). A seleção dos microrganismos baseou-se em experimentos similares realizados por outros pesquisadores (4, 12-14). Todos os testes foram realizados em duplicata.

\section{Tintura-mãe de arnica}

Foi utilizado extrato etanólico comercial de arnica, proveniente do Laboratório Boiron (França). A tintura-mãe é obtida a partir de uma 
mistura de água e álcool, na qual plantas frescas totais são maceradas por um período de 10 a 21 dias, paraaliberação dosprincípiosativos. A pósprensagem e filtração, são realizados testes pelo laboratório, quanto à ação da tintura-mãe assim obtida (15).

\section{Concentração inibitória mínima (CIM) / Concentração bactericida mínima (CBM)}

A CIM foi determinada através de testes de diluição seriada em caldo. O inóculo constituiu-se de colônias de bactérias, incubadas por 24--48 horas em Brain $\mathrm{H}$ eart Infusion A gar (BHI-Difco), diluídas em solução fisiológica 0,85\% e a concentração da suspensão ajustada ao tubo 0,5 da Escala de Mc Farland $(4,11,16)$. $O$ crescimento de $C$. albicans foi obtido em Sabouraud D ex trose A gar (D ifco) (4). Os ensaios de diluição em caldo foram realizados empregando-se Müeller H inton Broth (D ifco) para 0 crescimento de bactérias $(11,16)$ e Sabouraud D ex trose Broth (Difco) (4) para C. albicans, sem adição de soluções-tampão $(4,11,16)$. A tintura-mãe de arnica foi diluída de forma a se testar as seguintes concentrações finais: $100,00 \mu \mathrm{L} / \mathrm{mL} ; 50,00 \mu \mathrm{L} / \mathrm{mL}$; $25,00 \mu \mathrm{L} / \mathrm{mL} ; 12,50 \mu \mathrm{L} / \mathrm{mL} ; 6,25 \mu \mathrm{L} / \mathrm{mL} ; 3,13 \mu \mathrm{L} /$ $\mathrm{mL} ; 1,56 \mu \mathrm{L} / \mathrm{mL}$ e $0,78 \mu \mathrm{L} / \mathrm{mL}$.

\section{Realização do teste}

Uma vez que não há padronização para a detecção de sensibilidade dos microrganismos a extratos de plantas, adaptou-se o que há descrito na literatura na realização deste projeto $(4,11,16)$. Utilizaram-se oito tubos contendo caldo Müeller $\mathrm{H}$ inton, nos quais foram realizadas diluições seriadas na razão de 1:2. No primeiro tubo foram distribuídos $4,0 \mathrm{~mL}$ do meio e nos demais $2,0 \mathrm{~mL}$. Adicionou-seao primeiro tubo 0,4mL detintura-mãedeA rnica montana e, após homogenização, transferiu-se $2,0 \mathrm{~mL}$ ao segundo tubo e assim sucessivamente até o oitavo, obtendo-se então as concentrações de arnica (16) referidas acima. Mais dois tubos foram empregados, no nono foi adicionado meio de cultivo e $100 \mu \mathrm{L} / \mathrm{mL}$ de álcool etílico de cereais 70\% (diluente da tintura de arnica) e no décimo apenas o meio de cultivo, para controle positivo do crescimento microbiano (11, 16). A cada um dos tubos foram adicionados $10 \mu \mathrm{L} /$ $\mathrm{mL}$ do inóculo do microrganismo (16). As bactérias e fungos foram incubados a $37^{\circ} \mathrm{C}$ respectivamente, durante 24 e 48 horas $(4,11,16)$.
A CIM foiamenor concentração dearnica que inibiu o crescimento visível (turvação do meio de cultivo) $(4,16)$. A CBM foi determinada semeando-se a suspensão de cada um dos tubos do teste de CIM aonde 0 crescimento bacteriano foi inibido em ágar BHI e incubando-se este material pelo período já referido; a ausência de crescimento indicou ação bactericida efetiva (16).

\section{Difusão em ágar}

O inóculo, as diluições de arnica, a temperatura e os tempos de incubação foram os referidos anteriormente; os meios de cultivo foram os citados, entretanto na forma de ágar.

\section{Realização do teste}

Este teste foi realizado segundo a técnica de Kirby \& Bauer, na qual discos impregnados com a droga a ser ensaiada são colocados sobre uma placa de Petri com ágar, onde o microrganismo a ser testado foi semeado (17).

Suspensão de microrganismos, ao tubo 0,5 daescaladeMcFarland, foiespalhadasobreasuperfície do ágar com auxílio de swab estéril; após 15 minutos, foram adicionados discos de papel impregnados com as diluições de arnica (17). Discos estéreis de papel de filtro (diâmetro de 6,3mm) foram embebidos, por cinco vezes consecutivas, com as diferentes diluições datintura-mãe(16). Entrecadaum dosprocedimentos foi permitida a evaporação do solvente à temperatura ambiente, com exceção da última, quando os discos foram aplicados úmidos sobre a superfície do ágar (16). À semelhança do descrito para o teste de diluição em caldo, utilizou-se um disco contendo apenas álcool etílico de cereais 70\%. As placas de bactérias e fungos foram incubadas a $37^{\circ} \mathrm{C}$ respectivamente, durante 24 e 48 horas $(4,11,16)$.

A leiturafoirealizadamedindo-seo diâmetro do halo de inibição da droga. Executaram-se provas com antimicrobianos comerciais, como controle da sensibilidade dos microrganismos empregados.

\section{RESULTADOS}

No teste de CIM, verificou-se que, com exceção de B. subtilis frente a $100 \mu \mathrm{L} / \mathrm{mL}$, não houveinibição dosmicrorganismosàs concentrações 
de arnica testadas (Tabela 1). A CBM mínima, nesse caso, coincidiu com a CIM, pois quando a suspensão desse tubo foi semeada em ágar BHI, não ocorreu crescimento.

TABELA 1 - Comportamento de microrganismos frente diferentes concentrações de A rnica montana, em teste de Concentração Inibitória Mínima

\begin{tabular}{|c|c|c|c|c|c|c|c|c|c|}
\hline \multirow[b]{2}{*}{$\begin{array}{l}\text { Micror- } \\
\text { ganismos }\end{array}$} & \multirow[b]{2}{*}{$\begin{array}{l}100 \mu \mathrm{L} \\
/ \mathrm{mL}\end{array}$} & \multirow[b]{2}{*}{$\begin{array}{l}50 \mu \mathrm{L} \\
/ \mathrm{mL}\end{array}$} & \multicolumn{4}{|c|}{ Concentrações de A rnica montana } & \multirow[b]{2}{*}{$\begin{array}{l}\text { 1,56بL } \\
/ \mathrm{mL}\end{array}$} & \multirow[b]{2}{*}{$\begin{array}{l}0,78 \mu \mathrm{L} \\
/ \mathrm{mL}\end{array}$} & \multirow[b]{2}{*}{$\begin{array}{l}\text { Álcool } \\
\text { Etúlico } 70 \%\end{array}$} \\
\hline & & & $\begin{array}{l}25 \mu \mathrm{L} \\
/ \mathrm{mL}\end{array}$ & $\begin{array}{l}12,5 \mu \mathrm{L} \\
/ \mathrm{mL}\end{array}$ & $\begin{array}{l}6,25 \mu \mathrm{L} \\
\text { / } \mathrm{mL}\end{array}$ & $\begin{array}{l}3,12 \mu \mathrm{L} \\
/ \mathrm{mL}\end{array}$ & & & \\
\hline B. subtilis & $-*$ & + & + & + & + & + & + & + & + \\
\hline E . faecalis & + & + & + & + & + & + & + & + & + \\
\hline S. aureus & + & + & + & + & + & + & + & + & + \\
\hline P. aeruginosa & + & + & + & + & + & + & + & + & - \\
\hline E. coli & + & + & + & + & + & + & + & + & + \\
\hline C. albicans & + & + & + & + & + & + & + & + & - \\
\hline
\end{tabular}

*Crescimento: +; Ausência de crescimento: -

Em relação à difusão em ágar, observou-se inibição de P. a eruginosa frente a todas as concentrações de arnica e ao etanol (Tabela 2), não se verificando diferenças entre o diâmetro dos halos das diferentes concentrações de arnica e do obtido apenas com o álcool de cereais (Tabela 2).

TABELA 2 - Comportamento de microrganismos frente diferentes concentrações de A rnica montana, em teste de difusão em ágar

\begin{tabular}{|c|c|c|c|c|c|c|c|c|c|}
\hline \multirow[b]{2}{*}{$\begin{array}{l}\text { Micror- } \\
\text { ganismos }\end{array}$} & \multirow[b]{2}{*}{$\begin{array}{l}100 \mu \mathrm{L} \\
/ \mathrm{mL}\end{array}$} & \multirow[b]{2}{*}{$\begin{array}{l}50 \mu \mathrm{L} \\
/ \mathrm{mL}\end{array}$} & \multicolumn{4}{|c|}{ Concentrações de A rnica montana } & \multirow[b]{2}{*}{$\begin{array}{l}1,56 \mu \mathrm{L} \\
/ \mathrm{mL}\end{array}$} & \multirow[b]{2}{*}{$\begin{array}{l}0,78 \mu \mathrm{L} \\
/ \mathrm{mL}\end{array}$} & \multirow[b]{2}{*}{$\begin{array}{l}\text { Álcool } \\
\text { Et́ilico } 70 \%\end{array}$} \\
\hline & & & $\begin{array}{l}25 \mu \mathrm{L} \\
/ \mathrm{mL}\end{array}$ & $\begin{array}{l}12,5 \mu \mathrm{L} \\
/ \mathrm{mL}\end{array}$ & $\begin{array}{l}6,25 \mu \mathrm{L} \\
/ \mathrm{mL}\end{array}$ & $\begin{array}{l}3,12 \mu \mathrm{L} \\
/ \mathrm{mL}\end{array}$ & & & \\
\hline B. subtilis & - & - & - & - & - & - & - & - & - \\
\hline E . faecalis & - & - & - & - & - & - & - & - & - \\
\hline S. aureus & - & - & 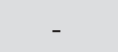 & - & - & - & 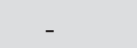 & - & _. \\
\hline P. aeruginosa & $12 *$ & 11 & 10 & 13 & 18 & 11 & 14 & 15 & 12 \\
\hline E. coli & - & - & - & - & - & - & - & - & - \\
\hline C. albicans & - & - & 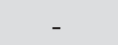 & - & - & 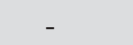 & - & - & - \\
\hline
\end{tabular}

*Diâmetro do halo de inibição em mm; Ausência de halo de inibição

\section{DISCUSSÃO}

Em relação à A rnica montana os compostos ativos principais são as lactonas sesquiterpênicas, como a helenalina $(1,3)$ e, embora já tenham sido demonstrados seus efeitos antiedematoso e antiinflamatório, são poucos os estudos sobre sua ação nos microrganismos.

A emergência de microrganismos multirresistentes tem impulsionado pesquisas de substâncias alternativas, que possam ser empregadas como antimicrobianos. D essa forma, diversos óleos e extratos de plantas vêm sendo testados quanto à sua capacidade de controlar e inibir o crescimento de bactérias e fungos $(4,13,14,18)$; entretanto, como ainda não existem técnicas padronizadas para a execução desses testes, resultados de inibição encontradosin vitro deverão sermelhorcompreendidos antesquesepossaindicarsuaaplicabilidadeterapêutica.

Em vista da falta de padronização, adaptou-se o que há descrito na literatura para a realização desta pesquisa. Os microrganismos utilizados neste projeto são frequentemente escolhidos para testes de sensibilidade $(4,12-14)$, 
por serem agentes comuns de doenças e/ ou apresentarem alto padrão de resistência aos antimicrobianos.

A CIM foi obtida pela técnica de macrodiluição, que permite visualização do crescimento dos microrganismosatravés da turvação do meio de cultura (16). Nesta pesquisa só se obteve inibição de crescimento de $B$. subtilis no teste de CIM, com concentração de $100 \mu \mathrm{L} / \mathrm{mL}$ de arnica, não se detectando ação das diferentes concentrações da tintura nos microrganismos experimentados. Na mesmalinha, em experimentos sobre a ação da arnica em patógenos orais, verificouse ação antimicrobiana apenas discreta contra algumas espécies de Streptococaus (12), A ctinomyces naeslundii e Porphyromonas gingivalis (11). Entretanto, outros autores encontraram valores aceitáveis de CIM para Porphyromonas gingivalis, Prevotella sp, E ik enella corrodens, Peptostreptococaus sp e A ctinomyces sp, indicando autilização dearnica como antisséptico para higiene da cavidade oral (19). Talvez as diferenças verificadas entre os pesquisadores reflitam a falta de padronização para esses testes, 0 que dificulta o cotejamento de resultados.

Quanto ao método de difusão em ágar, utilizou-se a técnica padrão internacional para testes de sensibilidade para bactérias frente aos antibacterianos (17), por ser de extrema facilidade de execução e, se houvesse ocorrido halos de inibição frente à arnica, estes poderiam ser comparados com os obtidos com os antibióticos convencionais. Nesta prova apenas $P$. aeruginosa teve inibição de crescimento frente aos extratos de arnica; entretanto, essa bactéria também apresentou sensibilidade ao álcool etílico decereais, queéempregado na produção da tintura dessa planta. Os diâmetros dos halos obtidos frente à arnica e ao álcool etílico foram similares, revelando a importância desse controle alcoólico pois, se não tivesse sido utilizado, seriam falso-positivos os resultados de inibição de $P$. aeruginosa pela arnica. Iauk et al. (19) verificaram sensibilidade de bactérias isoladas de doença periodontal à arnica empregando extratos etanólicos, porém não utilizaram controle alcoólico, o que gera dúvidas se a ação foi decorrente da planta ou do álcool. Deve-se ainda aventar que a ausência de inibição dos microrganismos frente às diferentes concentrações de arnica pode ser decorrente da falta ou pequena difusão do extrato da planta no ágar.
Embora a arnica seja largamente usada como fitoterápico e homeopático, nas condições experimentais, não se verificou ação que possa indicar sua utilização como antimicrobiano. Entretanto, pesquisas nesse campo devem ser incentivadas e aprimoradas, na busca de drogas e princípios ativos alternativos, principalmente devido à crescente aquisição de resistência pelas bactérias e fungos aos antimicrobianos tradicionalmente utilizados.

\section{REFERÊNCIAS}

1. Martins ER, Castro D M, Castellani D C, D ias JE. Plantas medicinais. Viçosa (Brasil): Imprensa Universitária; 1994.

2. Benez SM, Boericke W, Cairo N, Jacobs PH, Macleod G, Schroyens F et al. Manual de homeopatia veterinária. São Paulo: Robe; 2002.

3. Alves TMA, Silva AF, Brandão M, Grandi TSM, Ismânia EFA, Júnior A S, et al. Biological screening of Brazilian medicinal plants. Mem Inst O swaldo Cruz. 2000;95:367-73.

4. Klaas CA, Wagner G, Laufer S, Sosa S, Loggia RD, Bomme U, et al. Studies on the antiinflamatory activity of phytopharmaceuticals prepared from A rnica flowers. Planta Med. 2002;68:385-91.

5. Sartoratto A, Machado ALM, D elarmelina C, Figueira GM, D uarte MCT, Rehder VLG. Composition and antimicrobial activity of essential oils from aromatic plants used in Brazil. Braz J Microbiol. 2004;35:275-80.

6. Carvalho AC, Bonamin LV. Efeitos da administração de A rnica montana (tintura-mãe e preparações dinamizadas $6 \mathrm{CH}$ ) na atividade de diferentes agentes flogísticos em ratos. Rev Pesq Homeop. 2001;16:31-43.

7. Pereira PSS. Avaliação clínica da eficácia da A rnica montana no controle da dor, edema e trismo pós-operatório na cirurgia de terceiros molares mandibulares retidos [dissertação]. Brasília: Faculdade de Ciências da Saúde da Universidade de Brasília; 1999.

8. Daane SP. Potential for danger with A rnica montana. Ann Plast Surg. 2001;46:349-50. 
9. François G, Passreiter CM. Pseudoguaianolide sesquiterpene lactones with high activities against the human malaria parasite Plasmodium falciparum. Phytoth Res. 2004;18:184-6.

10.Schmidt TJ, Brun R, Willuhn G, Khalid SA. Anti-trypanossomal activity of helenalin and some structurally related sesquiterpene lactones. Planta Med. 2002;68:750-1.

11. Koo H, Gomes BPA, Rosalen PL, Ambrosano GB, Park YK, Cury JA. In vitro antimicrobial activity of propolis and A rnica montana against oral pathogens. Arch Oral Biol. 2000;45:141-8.

12. Nardy R, Nascimento CM, Jorge AOC, Zelante PM. Análise da ação antimicrobiana das medicações Calendula, Arnica e Echinacea. In: Reuniẫo Anual da Sociedade Brasileira de Pesquisa Odontológica, 17. Águas de Lindóia, 2000. Anais. p. 746. [O nline] 2000. Disponível em URL: http:// www.odontologia.com.br/ paineis.asp?id=746

13.Ahmad I, Beg AZ. Antimicrobial and phytochemical studies on 45 Indian medicinal plants against multi-drug resistant human pathogens. J Ethnopharmacol. 2000;74:113-23.

14. Ali-Shtayeh MS, Yaghmour RMR, Faidi YR, Salem $\mathrm{K}$, Al-Nuri MA. Antimicrobial activity of 20 plants used in folkloric medicine in the Palestinian area. J Ethnopharmacol. 1998;60:265-71.
15.Preparation of homeopathic drugs. [O nline] 2007. [cited 2007 jan 02] Disponível em: URL: http:/ / www.boiron.com

16. Pizsolitto AC, Pozetti G L. Avaliação comparativa da ação antibacteriana de tinturas-mãe de Thuya occidentalis. Rev Pesq Homeop. 1987;3:33-9.

17. Bauer AW, Kirby WMM, Sherris JC, Turck M. Antibiotic susceptibility testing by standardized single disk method. Am J Clin Pathol. 1966;45:493-6.

18. Helander IM, Alakomi HL, Latva-Kala K, Mattitila-Sandholm T, Pol I, Smid EJ, et al. Characterization of the action of selected essential oil components on gram-negative bacteria. J Agric Food Chem. 1998;46:3590-5.

19.Iauk L, Bue AML, Milazzo I, Rapisarda A, Blandino G. Antibacterial activity of medicinal plant extracts against periodontopathic bacteria. Phytother Res. 2003;17:599-604.

Recebido: 03/ 02/ 2007 Received: 02/ 03/ 2007

Aprovado: 12 / 03/ 2007

A pproved: 03/ 12/ 2007 